\title{
Influence of Force Tremor on Mechanomyographic Signals Recorded with an Accelerometer and a Condenser Microphone during Measurement of Agonist and Antagonist Muscles in Voluntary Submaximal Isometric Contractions
}

\author{
Tae-Kwang Kim $^{1)}$, Yoshihiro Shimomura ${ }^{2)}$, Koichi Iwanaga ${ }^{2)}$ and Tetsuo Katsuura ${ }^{2)}$ \\ 1) Graduate School of Science and Technology, Chiba University \\ 2) Faculty of Engineering, Chiba University
}

\begin{abstract}
The purpose of this study was to investigate the influence of force tremor (FT) on the mechanomyogram (MMG) recorded by a condenser microphone (MIC) and an accelerometer (ACC) for the measurement of agonist and antagonist muscles during submaximal isometric contractions. Following determination of the isometric maximum voluntary contraction (MVC), 10 male subjects were asked to perform elbow flexion and extension at $20 \%, 40 \%, 60 \%$, and $80 \%$ MVC. Surface electromyogram (EMG) and MMG of the biceps brachii $(\mathrm{BB})$ and triceps brachii $(\mathrm{TB})$ were recorded simultaneously using a MIC (MMG-MIC) and an ACC (MMG${ }_{\mathrm{ACC}}$ ). We analyzed the root mean square (RMS) for all signals and compared the sum of the power spectrum amplitude (SPA) at $3-6 \mathrm{~Hz}$ and $8-12 \mathrm{~Hz}$ between the MMG-MIC and the MMGACC. During elbow flexion and extension, the RMS of the EMG and the MMG- ${ }_{\text {MIC }}$ of the agonist were significantly $(p<0.05)$ higher than those of the antagonist in each contraction level. The RMS of the MMG- ${ }_{\text {ACC }}$ of the antagonist showed no significant $(p>0.05)$ difference from that of the agonist, or tended to be higher than the agonist. The SPA of the MMG-MIC of the agonist at $3-6 \mathrm{~Hz}$ and $8-12 \mathrm{~Hz}$ tended to be higher than the antagonist in elbow flexion and extension at each contraction level. The SPA of the MMG- ${ }_{\text {ACC }}$ of the agonist and that of the antagonist showed no significant $(p>0.05)$ difference, or the antagonist MMG- ${ }_{\text {ACC }}$ tended to be higher than that of the agonist. These results suggest the MMG detected by a MIC appears to be less affected by FT than is the ACC because of its inherent characteristic to reduce FT in simultaneously evaluated agonist and antagonist muscles by means of MMG during submaximal isometric contraction. J Physiol Anthropol 27(1): 33-42, 2008 http:// www.jstage.jst.go.jp/browse/jpa2
\end{abstract}

[DOI: 10.2114/jpa2.27.33]

Keywords: mechanomyogram, force tremor, agonist, antagonist, condenser microphone, accelerometer

\section{Introduction}

It is well known that during voluntary muscle contraction the antagonist muscles generate relatively smaller force simultaneously in the direction counter to agonist muscle activity (Smith, 1981; Gamet and Maton, 1989). Therefore, studies that measure and analyze the antagonistic muscle pairs have been performed to evaluate the physiological aspects of muscles (Shibata and Moritani, 1991; Bernardi et al., 1997; Gamet and Maton, 1989; Psek and Cafarelli, 1993; Ebenbichler et al., 1998). Because surface electromyography (EMG) can quantify the activity of antagonistic muscle pairs, EMG has been commonly used as a tool to evaluate agonistantagonist muscle activity (De Vito et al., 2003).

Recently, the mechanomyogram (MMG) has been proposed as another tool with which to evaluate muscle activity (Mamaghani et al., 2001). The MMG record and quantify mechanical low-frequency vibration produced by lateral oscillations at the skin surface of active muscles (Orizio, 1993; Gordon and Holbourn, 1948; Stokes and Dalton, 1991; Barry et al., 1985), and it is considered that MMG reflects the mechanical aspect of muscle activity in its strategy of motor unit recruitment and firing rate (Orizio, 1993; Stokes and Dalton, 1991). The EMG reflects the electrical aspect as action potentials relates to muscle activity (Stokes and Dalton, 1991; De Luca, 1997).

The muscles' mechanical vibrations include not only inner muscular vibration, but also force tremor (FT) and motion artifacts due to large movements of the body (Tarata, 2003). However, FT (Barry, 1987; Oster and Jaffe, 1980; Itoh et al., 2000; Goldenberg et al., 1991; Orizio, 1993) and motion artifacts (Tarata, 2003; Watakabe et al., 2001) have been 
considered to affect the interpretation of $\mathrm{MMG}$ signals. Isometric muscle contraction is accompanied by FT (Allum et al., 1978; Brown et al., 1982). The FT has a broad frequency bandwidth of between 1 and $25 \mathrm{~Hz}$ (Allum et al., 1978) and the majority of the FT's frequency bandwidth is in the $3-6 \mathrm{~Hz}$ bandwidth related to reflex activity, while the $8-12 \mathrm{~Hz}$ bandwidth is related to physiological tremor (Brown et al., 1982; Prochazka and Trend, 1988). Since the main frequency content of the MMG is below $100 \mathrm{~Hz}$ (Oster and Jaffe, 1980), it is possible that the frequency spectrums of the FT and the MMG signals overlap. Several researchers have attempted to eliminate or separate FT from MMG signals through the use of a Fourier truncation (Goldenberg et al., 1991) or through the use of coherence analysis (Itoh et al., 2000). Barry (1987) argued that it is necessary to remove the influence of FT from MMG signals since the FT may affect MMG signals. Thus, it is necessary to find a method to reduce or eliminate the interfusion of FT with MMG.

To detect MMG signals, transducers such as piezoelectric contact sensors, condenser microphones, and accelerometers have been used (Watakabe et al., 2001). However, piezoelectric contact sensors have been found to have a disadvantage in that they have difficulty in measuring small muscles because of the transducer's relatively great mass (Orizio, 1993) and changes in the MMG signals induced by the contact pressure of the transducer during recording (Smith and Stokes, 1993; Orizio, 1993; Orizio, 2004). Condenser microphones are relatively light and are not affected by contact pressure (Itoh et al., 2001). However, they have a complicated structure because they require a chamber for coupling between the muscle surface and the microphone (Goldenberg et al., 1991). In addition, the volume of the chamber affects the MMG recording (Watakabe et al., 2001). Due to their small size and weight, accelerometers can be applied to small muscles, thus allowing easy attachment (Barry, 1992). However, they are more sensitive to FT than are other transducers (Smith and Stokes, 1993). The MMG signals recorded by different transducers differ in frequency response because of each type of transducer's inherent characteristics (Orizio, 1993). Beck et al. (2006) compared MMG signals recorded by a piezoelectric contact sensor and an accelerometer during dynamic and isometric torque contraction and found differences between both transducers in terms of amplitude and frequency, and concluded that the MMG transducer may affect the interpretation of MMG signals. Bolton et al. (1989) reported that the condenser microphone and the piezoelectric contact sensor show similar frequency response and shape, differing from those shown by the accelerometer (Watakabe et al., 2001). In particular, an accelerometer can be influenced by measurement location (Cescon et al., 2004) and is more strongly affected by movement artifacts than a condenser microphone (Watakabe et al., 2001). Jaskolska et al. (2007) reported that the MMG signals detected by a condenser microphone and accelerometer show different behaviors in regard to frequency and amplitude during eccentric contraction. It is suggested that the different behaviors of two transducers are caused by both transducers which differing the influence of movement artifacts. Thus, the microphone condenser and accelerometer may be affected differently by FT.

The aim of this study is to investigate the influence of FT on MMG recorded by a condenser microphone and an accelerometer for the measurement of agonist and antagonist muscles during submaximal isometric contractions.

\section{Methods}

\section{Subjects}

Ten healthy male volunteers (right-handed) without any muscular disorders in the arm and shoulder region participated in the experiments. The mean $\pm \mathrm{SD}$ data of age, height, and body mass were $23.2 \pm 1.5$ years, $1.71 \pm 0.06 \mathrm{~m}$, and $61.5 \pm 8.2 \mathrm{~kg}$, respectively. The subjects were non-athletes who experienced moderate levels of physical activity. Informed consent was obtained from all participants.

\section{Protocol and procedures}

The subject sat comfortably in an upright position on a chair with an elbow joint angle of $90^{\circ}$. The waist, chest, and shoulder were fixed with a belt to prevent movement during the task. The forearm was in a supinating position on the sagittal plane and not supported during the test. A strain gauge dynamometer (No 1269, Takei Kiki Kogyo Co) was connected to a belt around the waist. In order to ensure that the subject maintained the required posture during the task, the subject was asked to maintain his posture using a marker indicating the height of the forearm at an elbow joint angle of $90^{\circ}$. In addition, visual feedback provided by a video camera system was used to allow the subject to observe his performance and elbow angles (Fig. 1b). Prior to the isometric test, the subjects underwent three randomly ordered 5-s elbow flexion and extension maximum voluntary contraction (MVC) measurements with a $5 \mathrm{~min}$ rest between trials. The elbow flexion and extension MVC was measured by means of a strain gauge dynamometer fixed to the bottom and upper side of a metal frame, respectively. The MVC was determined by the highest force value in the MVC measurement. After a $10 \mathrm{~min}$ rest, the subject performed 6-s elbow flexion and extension isometric contractions at 20\%,40\%,60\%, and $80 \%$ MVC in randomized order. A $5 \mathrm{~min}$ rest was allowed between each muscle contraction trials. Visual feedback corresponding to each force level was provided (Fig. 1b).

\section{EMG and $M M G$ signal recording}

Surface EMG and MMG were recorded simultaneously. The MMG signals were detected using a condenser microphone (MIC) and accelerometer transducer (ACC). Both of the MMG's transducers were attached by means of double-sided adhesive tape adjacent to each other over the biceps brachii (BB) and triceps brachii (TB) muscle belly. The ACC was 
a)

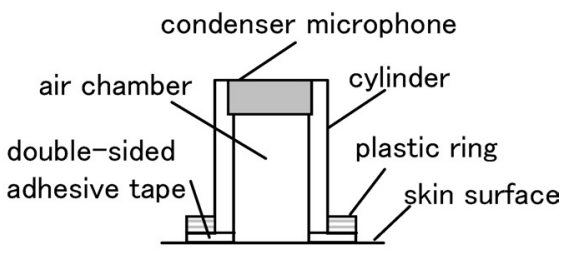

b)

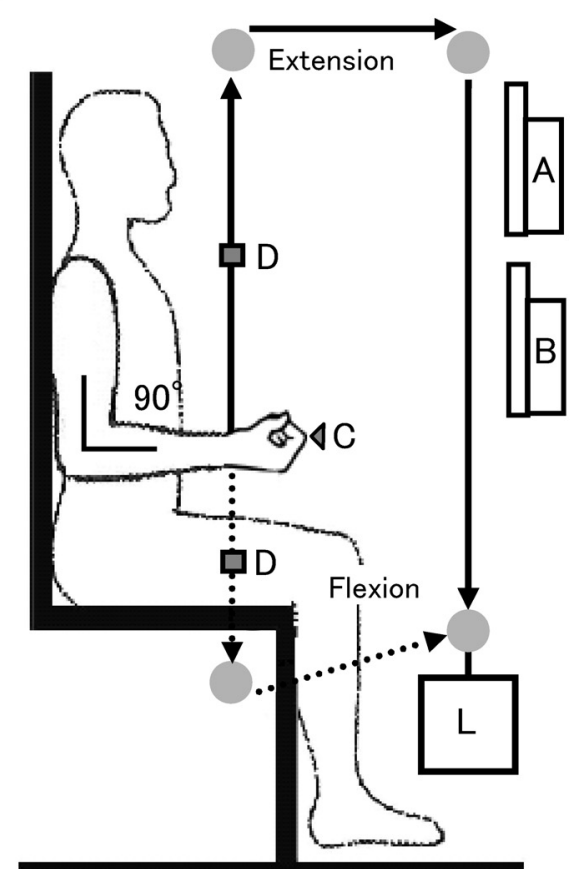

Fig. 1 a) Schematic drawing of mechanomyographic (MMG) sensor using a condenser microphone (Watakabe et al., 2001). The airchamber has a diameter of $10 \mathrm{~mm}$ and a height of $15 \mathrm{~mm}$. b) Schematic drawing of the experimental set-up. A: visual feedback of force level, B: visual feedback for position of the hand and elbow angle, C: marker for forearm height, D: strain gauge dynamometer, L: load by $\% \mathrm{MVC}, \rightarrow$ : wire direction during flexion and extension.

positioned distal to the MIC. The MMG- ${ }_{\text {MIC }}$ signal was detected by a MIC (EM162S5A, PRIMO, bandwidth $1 \mathrm{~Hz}-10$ $\mathrm{kHz}$, diameter $10 \mathrm{~mm}$, height $5.4 \mathrm{~mm}$, weight $1 \mathrm{~g}$, sensitivity $-41 \mathrm{~dB} \pm 3 \mathrm{~dB}$ at $100 \mathrm{~Hz}, 0 \mathrm{~dB}=1 \mathrm{~V} / \mathrm{Pa}$ ). The air chamber (diameter $10 \mathrm{~mm}$, height $15 \mathrm{~mm}$ ) of a plastic cylinder was joined to the MIC and it was fixed on the skin surface by a plastic ring (Fig. 1a). The MMG- ${ }_{\text {ACC }}$ signal was recorded by an ACC (S13S5H62A, PRIMO, bandwidth $1-300 \mathrm{~Hz}$, diameter $10 \mathrm{~mm}$, height $5.1 \mathrm{~mm}$, weight $1 \mathrm{~g}$, sensitivity $-34 \mathrm{~dB} \pm 3 \mathrm{~dB}$ at $6 \mathrm{~Hz}, 0 \mathrm{~dB}=1 \mathrm{~V} / 0.1 \mathrm{G})$. Surface EMG, incorporating a built-in gain amplifier, was recorded using surface electrodes (TSD150, BIOPAC systems, Gain 350, bandwidth $12-500 \mathrm{~Hz}$, input impedance $100 \mathrm{M} \Omega$, dimensions; $17.4 \times 51 \times 6.4 \mathrm{~mm}$, weight $9.5 \mathrm{~g}$ ). The EMG electrodes were positioned close to the MMG of both transducers on the longitudinal axis of the muscle.

All signals were converted from analog to digital at a $1 \mathrm{kHz}$ sampling rate (A/D converter: BIOPAC Systems, Model MP-
100-CE), and were stored in a computer. Prior to data analysis, the raw EMG, $\mathrm{MMG}_{{ }_{\mathrm{MIC}}}$, and $\mathrm{MMG}_{{ }_{\mathrm{ACC}}}$ data were digitally filtered off-line in a bandwidth of $10-500 \mathrm{~Hz}$ for the EMG, and $3-100 \mathrm{~Hz}$ for both MMGs. The EMG and MMG data were computed in 4-s intermediate periods based on the 6-s measurements of each trial.

\section{Signal processing}

To compare the frequency characteristics of the MMG- ${ }_{\mathrm{MIC}}$ and $\mathrm{MMG}_{\mathrm{ACC}}$ between the $\mathrm{BB}$ and the $\mathrm{TB}$, the power spectrum was computed using fast Fourier transformation (the Hanning windows, 1024 point) for the MMG signals of both transducer, and the sums of the power spectrum amplitude (SPA) for the $3-6 \mathrm{~Hz}$ and $8-12 \mathrm{~Hz}$ frequency bands were computed. To assess the amplitude characteristics of the EMG and the $\mathrm{MMG}_{\mathrm{MIC}}$ and $\mathrm{MMG}{ }_{\mathrm{ACC}}$, the root mean square (RMS) was computed.

\section{Statistical analysis}

In order to analyze the RMS and the SPA, the two-way (BB, $\mathrm{TB} \times \% \mathrm{MVC}$ ) repeated measures analyses of variance (ANOVA) was performed regarding the EMG and MMGand $\mathrm{MMG}_{\mathrm{ACC}}$, respectively. When appropriate in ANOVA, follow-up analyses included one-way (\%MVC) repeated measures ANOVA. Paired t-tests were performed at each contraction level to determine the presence of a significant mean difference between the $\mathrm{BB}$ and $\mathrm{TB}$.

\section{Results}

\section{Root mean square (RMS) for EMG and $M M G$}

The results of the two-way (BB, TB $\times \% \mathrm{MVC}$ ) and one-way ANOVA (\%MVC) are given in Table 1. The two-way repeated measures ANOVA for the EMG and the MMG-$_{\text {MIC }}$ and MMG- $_{\text {ACC }}$ indicated a significant $(p<0.05)$ interaction in flexion and extension, respectively. In the EMG and the MMG- $_{\mathrm{MIC}}$ and $\mathrm{MMG}_{\mathrm{ACC}}$, the one-way repeated measures ANOVA for the BB and the TB in flexion and extension indicated significant $(p<0.001)$ differences in each contraction level, respectively. The paired t-test results showed that the agonist RMS of the EMG and MMG-MIC were significantly $(p<0.05)$ higher than that of the antagonist at each contraction level during elbow flexion and extension (Figs. 2a, b). The RMS of MMG- ${ }_{\text {ACC }}$ showed no significant $(p>0.05)$ difference between the agonist and the antagonist, except for at $80 \%$ MVC during flexion and $60 \%$ and $80 \%$ MVC in extension (Fig. 2c). At $80 \%$ MVC during extension, the antagonist was significantly $(p<0.05)$ higher than the agonist. At $80 \%$ MVC during flexion and $60 \% \mathrm{MVC}$ in extension, the antagonist tended to be higher than the agonist $(p<0.1)$.

The sum of power spectrum amplitude (SPA) at 3-6 Hz and $8-12 \mathrm{~Hz}$

3-6 Hz: The results of the two-way $(\mathrm{BB}, \mathrm{TB} \times \% \mathrm{MVC})$ and one-way ANOVA (\%MVC) are given in Table 1. In the 
Table 1 Two-way repeated measures ANOVA for EMG, MMG- ${ }_{\mathrm{MIC}}$ and MMG- ${ }_{\mathrm{ACC}}$ in flexion and extension. Effects of force level (FL: \%MVC), measurement muscle (MM: biceps brachii, triceps brachii) and interaction (Inter: force level $\times$ measurement muscle) on root mean square (RMS), sum of power spectrum amplitude (SPA) for $3-6 \mathrm{~Hz}$ and $8-12 \mathrm{~Hz}$. If two-way repeated measures ANOVA indicated a significant $(p<0.05)$ interaction, results of one-way (\%MVC) repeated measures ANOVA for biceps brachii $\left(\mathrm{T}_{\mathrm{BB}}\right)$ and triceps brachii $\left(\mathrm{T}_{\mathrm{TB}}\right)$ is shown. $\mathrm{F}$ : Variance ratio with degree of freedom. p: Level of significance.

\begin{tabular}{|c|c|c|c|c|c|c|}
\hline \multirow{2}{*}{$\begin{array}{l}\text { Flexi } \\
\text { RMS }\end{array}$} & \multicolumn{2}{|r|}{ Interaction of two-way ANOVA } & \multicolumn{4}{|c|}{ Main effect of two or, one-way ANOVA } \\
\hline & $\begin{array}{l}\text { EMG } \\
\text { MIC } \\
\text { ACC }\end{array}$ & $\begin{array}{ll}\text { Inter: } & \mathrm{F}_{3,27}=23.38, p<0.0001 \\
\text { Inter: } & \mathrm{F}_{3,27}=6.84, p=0.0014 \\
\text { Inter: } & \mathrm{F}_{3,27}=3.84, p=0.0206\end{array}$ & $\begin{array}{l}\mathrm{T}_{\mathrm{BB}}: \\
\mathrm{T}_{\mathrm{BB}}: \\
\mathrm{T}_{\mathrm{BB}}:\end{array}$ & $\begin{array}{l}\mathrm{F}_{3,27}=23.94, p<0.0001 \\
\mathrm{~F}_{3,27}=17.32, p<0.0001 \\
\mathrm{~F}_{3,27}=16.99, p<0.0001\end{array}$ & $\begin{array}{l}\mathrm{T}_{\mathrm{TB}} \\
\mathrm{T}_{\mathrm{TB}} \\
\mathrm{T}_{\mathrm{TB}}\end{array}$ & $\begin{array}{l}\mathrm{F}_{3,27}=10.46, p<0.0001 \\
\mathrm{~F}_{3,27}=16.99, p<0.0001 \\
\mathrm{~F}_{3,27}=9.651, p=0.0002\end{array}$ \\
\hline $3-6 \mathrm{~Hz}$ SPA & $\begin{array}{l}\text { MIC } \\
\text { ACC }\end{array}$ & $\begin{array}{ll}\text { Inter: } & \mathrm{F}_{3,27}=2.76, p=0.0617 \\
\text { Inter: } & \mathrm{F}_{3,27}=1.27, p=0.3054\end{array}$ & $\begin{array}{l}\text { MM: } \\
\text { MM: }\end{array}$ & $\begin{array}{l}\mathrm{F}_{1,9}=8.50, p=0.0172 \\
\mathrm{~F}_{1,9}=1.25, p=0.2920\end{array}$ & $\begin{array}{l}\text { FL: } \\
\text { FL: }\end{array}$ & $\begin{array}{l}\mathrm{F}_{3,27}=3.89, p=0.0196 \\
\mathrm{~F}_{3,27}=3.41, p=0.0317\end{array}$ \\
\hline $8-12 \mathrm{~Hz}$ SPA & $\begin{array}{l}\text { MIC } \\
\text { ACC }\end{array}$ & $\begin{array}{ll}\text { Inter: } & \mathrm{F}_{3,27}=3.85, p=0.0205 \\
\text { Inter: } & \mathrm{F}_{3,27}=2.09, p=0.1251\end{array}$ & $\begin{array}{l}\mathrm{T}_{\mathrm{BB}}: \\
\mathrm{MM}:\end{array}$ & $\begin{array}{l}\mathrm{F}_{3,27}=5.35, p=0.0051 \\
\mathrm{~F}_{1,9}=2.32, p=0.1619\end{array}$ & $\begin{array}{l}\mathrm{T}_{\mathrm{TB}}: \\
\mathrm{FL}:\end{array}$ & $\begin{array}{l}\mathrm{F}_{3,27}=5.30, p=0.0053 \\
\mathrm{~F}_{3,27}=2.78, p=0.0602\end{array}$ \\
\hline \multicolumn{7}{|l|}{ Extension } \\
\hline RMS & $\begin{array}{l}\text { EMG } \\
\text { MIC } \\
\text { ACC }\end{array}$ & $\begin{array}{ll}\text { Inter: } & \mathrm{F}_{3,27}=29.75, p<0.0001 \\
\text { Inter: } & \mathrm{F}_{3,27}=6.12, p=0.0026 \\
\text { Inter: } & \mathrm{F}_{3,27}=10.01, p=0.0001\end{array}$ & $\begin{array}{l}\mathrm{T}_{\mathrm{BB}} \\
\mathrm{T}_{\mathrm{BB}} \\
\mathrm{T}_{\mathrm{BB}}\end{array}$ & $\begin{array}{l}\mathrm{F}_{3,27}=14.91, p<0.0001 \\
\mathrm{~F}_{3,27}=25.37, p<0.0001 \\
\mathrm{~F}_{3,27}=37.48, p<0.0001\end{array}$ & $\begin{array}{l}\mathrm{T}_{\mathrm{TB}}: \\
\mathrm{T}_{\mathrm{TB}}: \\
\mathrm{T}_{\mathrm{TB}}:\end{array}$ & $\begin{array}{l}\mathrm{F}_{3,27}=33.51, p<0.0001 \\
\mathrm{~F}_{3,27}=20.09, p<0.0001 \\
\mathrm{~F}_{3,27}=42.78, p<0.0001\end{array}$ \\
\hline $3-6 \mathrm{~Hz}$ SPA & $\begin{array}{l}\text { MIC } \\
\text { ACC }\end{array}$ & $\begin{array}{ll}\text { Inter: } & \mathrm{F}_{3,27}=2.08, p=0.1258 \\
\text { Inter: } & \mathrm{F}_{3,27}=6.29, p=0.0022\end{array}$ & $\begin{array}{l}\text { MM: } \\
\mathrm{T}_{\mathrm{BB}}:\end{array}$ & $\begin{array}{l}\mathrm{F}_{1,9}=5.23, p=0.0480 \\
\mathrm{~F}_{3,27}=8.59, p=0.0004\end{array}$ & $\begin{array}{l}\text { FL: } \\
\mathrm{T}_{\mathrm{TB}} \text { : }\end{array}$ & $\begin{array}{l}\mathrm{F}_{3,27}=4.268, p=0.0137 \\
\mathrm{~F}_{3,27}=13.88, p<0.0001\end{array}$ \\
\hline $8-12 \mathrm{~Hz}$ SPA & $\begin{array}{l}\text { MIC } \\
\text { ACC }\end{array}$ & $\begin{array}{ll}\text { Inter: } & \mathrm{F}_{3,27}=3.29, p=0.0358 \\
\text { Inter: } & \mathrm{F}_{3,27}=10.30, p=0.0001\end{array}$ & $\begin{array}{l}\mathrm{T}_{\mathrm{BB}}: \\
\mathrm{T}_{\mathrm{BB}}:\end{array}$ & $\begin{array}{l}\mathrm{F}_{3,27}=7.32, p=0.0010 \\
\mathrm{~F}_{3,27}=11.41, p<0.0001\end{array}$ & $\begin{array}{l}\mathrm{T}_{\mathrm{TB}}: \\
\mathrm{T}_{\mathrm{TB}}:\end{array}$ & $\begin{array}{l}\mathrm{F}_{3,27}=5.35, p=0.0050 \\
\mathrm{~F}_{3,27}=9.18, p=0.0002\end{array}$ \\
\hline
\end{tabular}

$\mathrm{MMG}_{\text {MIC }}$, the two-way repeated measures ANOVA indicated both a significant $(p<0.05)$ main effect and no interaction during flexion and extension. The paired t-test results indicated that the agonist SPA of the MMG- ${ }_{\text {MIC }}$ was significantly $(p<0.05)$ higher than that of the antagonist at $20 \%$ and $80 \%$ MVC during flexion, and at $40 \%$ and $80 \%$ MVC during extension. At $40 \%$ and $60 \%$ MVC during flexion, the agonist tended to be higher than the antagonist $(p<0.1)$ (Fig. 3a).

In the $\mathrm{MMG}_{\mathrm{ACC}}$ during flexion, the two-way repeated measures ANOVA indicated a significant $(p<0.05)$ main effect of contraction level (\%MVC) and no interaction. During extension, the two-way repeated measures ANOVA indicated a significant $(p<0.01)$ interaction. The one-way repeated measures ANOVA for the BB and the TB indicated significant $(p<0.001)$ differences at each contraction level, respectively. The paired t-test results showed that the mean differences between the agonist and antagonist during flexion and extension were not significant $(p>0.05)$ except that the antagonist was significantly $(p<0.05)$ higher than the agonist at $60 \%$ and $80 \%$ MVC during extension (Fig. $3 \mathrm{~b}$ ).

8-12 Hz: The results of the two-way $(\mathrm{BB}, \mathrm{TB} \times \% \mathrm{MVC})$ and one-way ANOVA (\%MVC) are given in Table 1. The two-way repeated measures ANOVA for the $\mathrm{MMG}^{-}{ }_{\mathrm{MIC}}$ indicated significant $(p<0.05)$ interaction during flexion and extension. The one-way repeated measures ANOVA for the BB and the $\mathrm{TB}$ in flexion and extension indicated significant $(p<0.01)$ differences at each contraction level, respectively. The paired ttest result showed that the agonist SPA values of the MMG- ${ }_{\text {MIC }}$ were significantly $(p<0.05)$ higher than those of the antagonist during flexion at $20 \% \mathrm{MVC}$, and tended to be higher than those of the antagonist at $80 \% \mathrm{MVC}$ in flexion and $40 \%$ and $80 \%$ MVC during extension $(p<0.1)$ (Fig. 4a).

In ACC during flexion, the two-way repeated measures ANOVA indicated no significant $(p>0.05)$ main effects and no interaction. During extension, the two-way repeated measures ANOVA indicated a significant $(p<0.001)$ interaction. The one-way repeated measures ANOVA of the BB and the TB indicated significant $(p<0.001)$ differences at each contraction level, respectively. The paired t-test results showed that the mean differences between the agonist and the antagonist during flexion and extension were not significant $(p>0.05)$ except for at 20\% MVC during flexion and $40 \%$ and $80 \%$ MVC during extension (Fig. 4b). At 40\% and $80 \%$ MVC during extension, the antagonist was significantly $(p<0.05)$ higher than the agonist. At $20 \%$ MVC during flexion, the antagonist tended to be higher than the agonist $(p<0.1)$.

\section{Discussion}

In the present study the RMS of the agonist EMG was significantly higher than the antagonist $(p<0.05)$ during flexion and extension at each contraction level (Fig. 2a). This result was consistent with those of previous investigations (Bernardi et al., 1997; Gamet and, Maton, 1989; Psek and Cafarelli, 1993; Ebenbichler et al., 1998), which have also reported a higher EMG amplitude level in the agonist than in the antagonist. It has been reported that the relatively smaller activity of the antagonist increases joint stability (Milner et al., 1995) and prevents excessive force, which could lead to joint damage during muscle contraction (Ebenbichler et al., 1998). 
Flexion

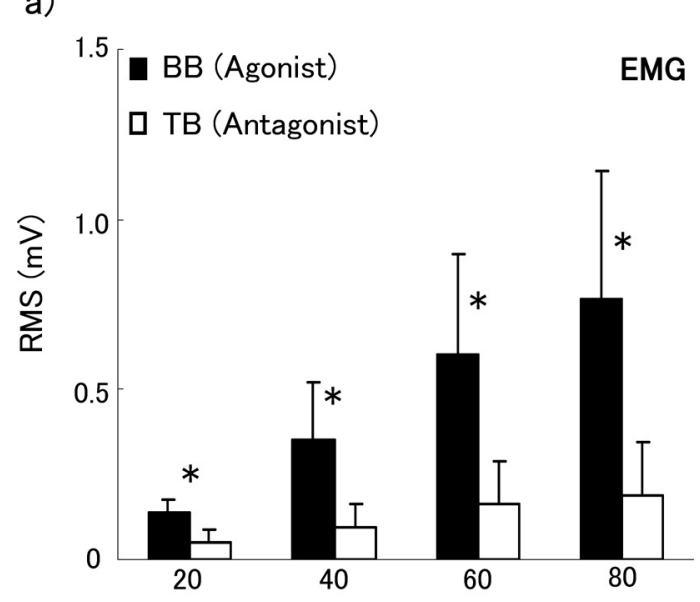

Extension

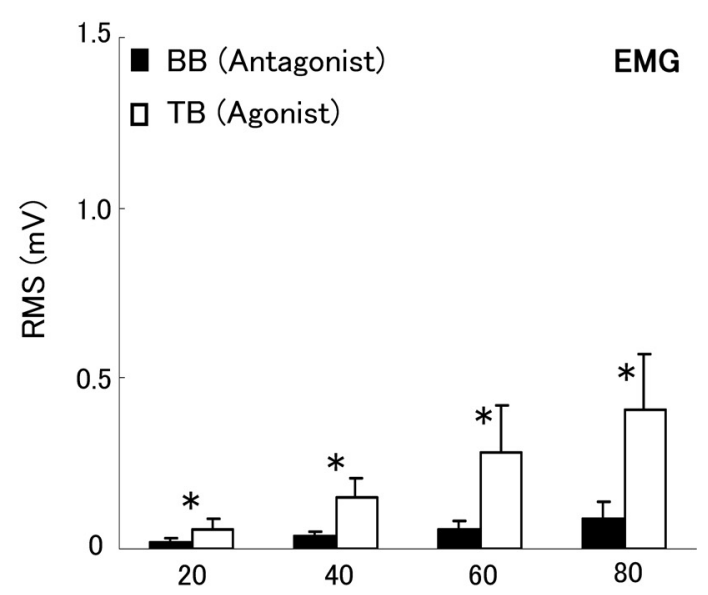

b)
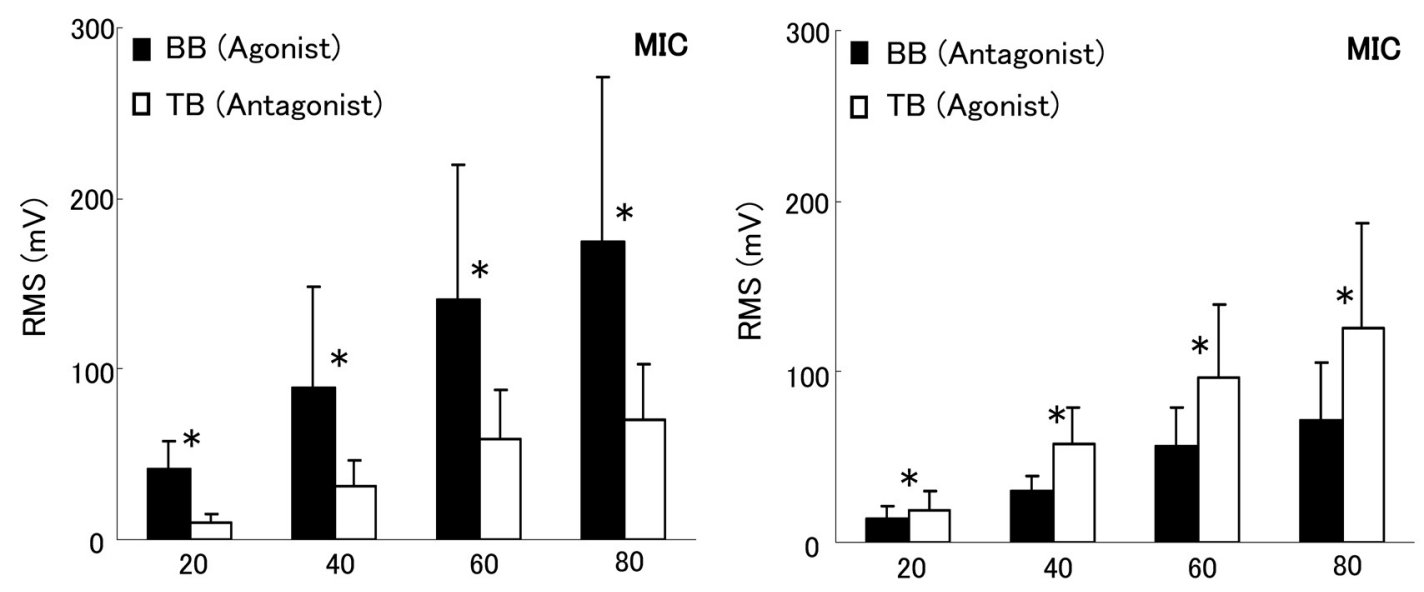

c)
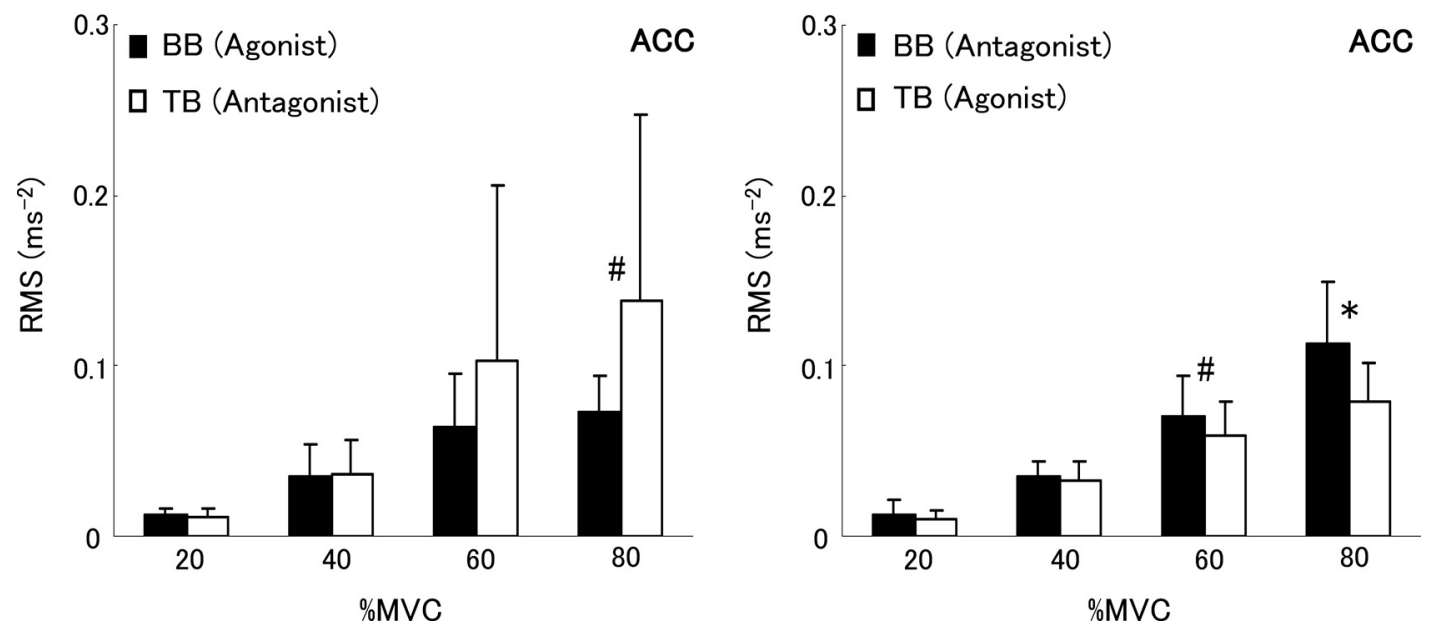

Fig. 2 Mean ( \pm SE) root mean square (RMS) values. a) RMS of electromyogram (EMG) in flexion [left panel] and extension [right panel]. b) RMS of the MMG recorded by microphone (MIC) during flexion [left pane] and extension [right panel]. c) RMS of the MMG recorded by accelerometer (ACC) during flexion [left panel] and extension [right panel]. $(*) p<0.05$, (\#) $p<0.1$ comparison between biceps brachii (BB) and triceps brachii (TB). MIC: $0 \mathrm{~dB}=1 \mathrm{~V} / \mathrm{Pa}, \mathrm{ACC}: 0 \mathrm{~dB}=1 \mathrm{~V} / 0.1 \mathrm{G}$. 
Flexion

a)

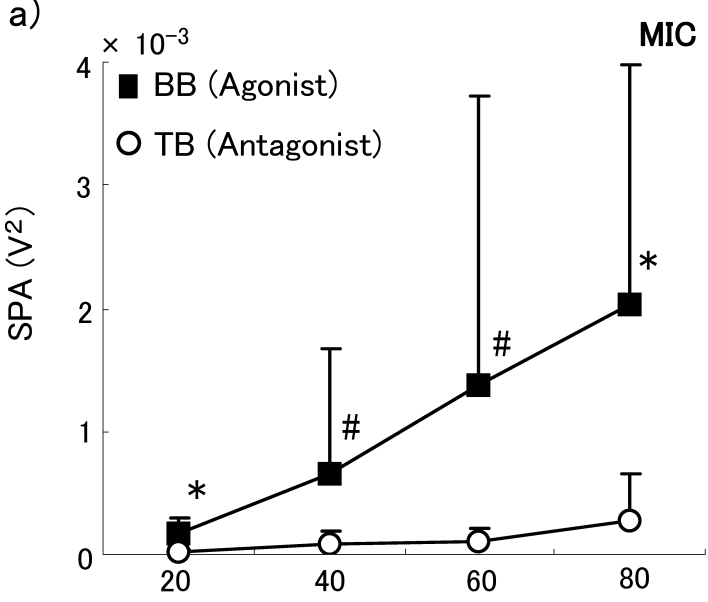

Extension

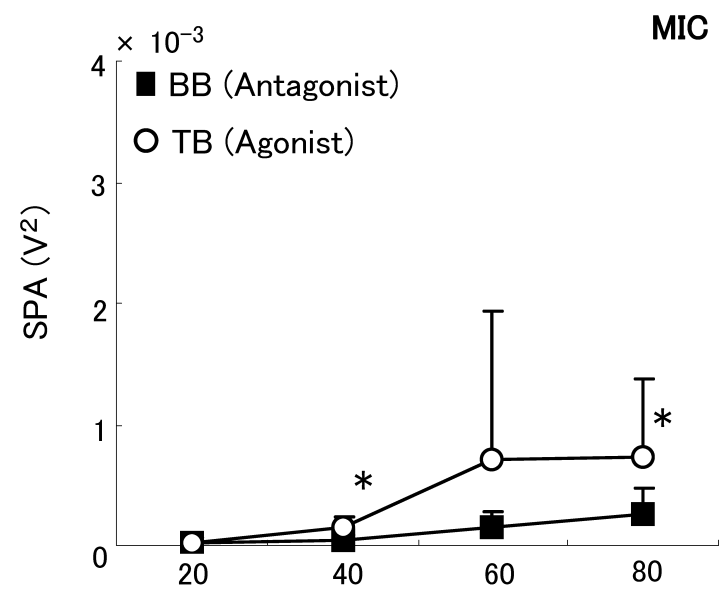

b)

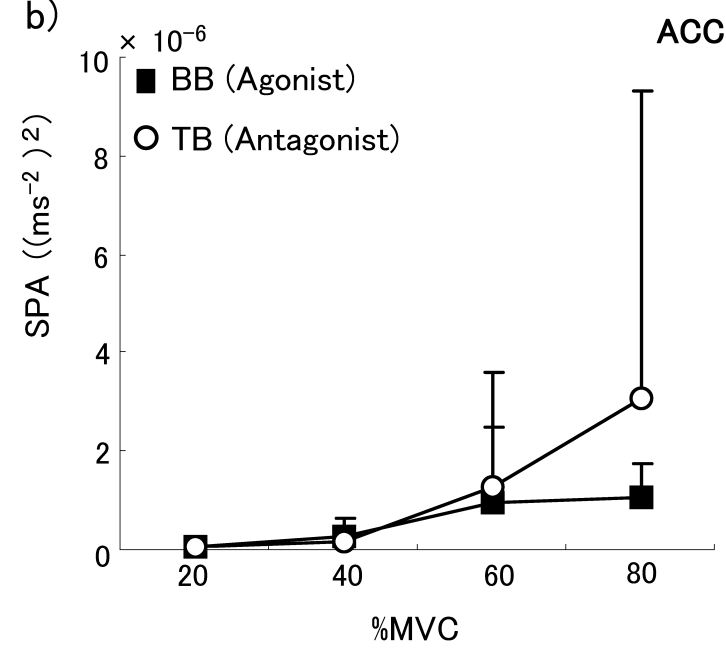

ACC

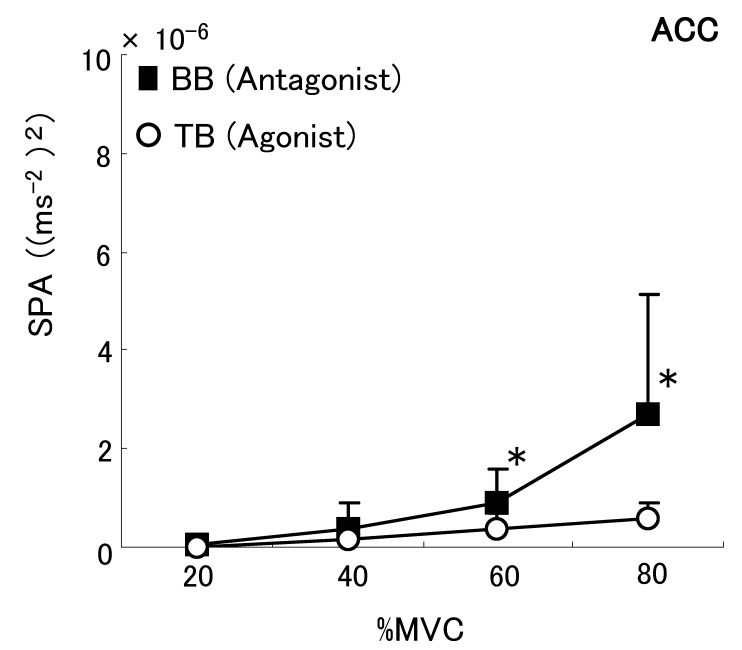

Fig. 3 Mean $( \pm$ SE) sum of power spectrum amplitude (SPA) values of the 3-6 Hz frequency bandwidth. a) SPA of the MMG recorded by microphone (MIC) during flexion [left panel] and extension [right panel]. b) SPA of the MMG recorded by accelerometer (ACC) during flexion [left panel] and extension [right panel]. (*) $p<0.05$, (\#) $p<0.1$ comparison between biceps brachii (BB) and triceps brachii (TB). MIC: $0 \mathrm{~dB}=1 \mathrm{~V} / \mathrm{Pa}$, ACC: $0 \mathrm{~dB}=1 \mathrm{~V} / 0.1 \mathrm{G}$.

The MMG assesses muscle activity by recording small mechanical vibrations that occur during muscle activity. Gordon and Holbourn (1948) reported that MMG signals reflect the mechanical counterpart of the motor unit electrical activity as detected by EMG. Tarata et al. (1997) reported that EMG and MMG signals simultaneously detected from the same muscle express similar behavior. In regard to the relationship between MMG and force level, a large number of studies have reported that the MMG amplitude is linearly increased to nearly $80 \%$ MVC. However, two opinions exist regarding MMG amplitude between $80 \%$ and 100\% MVC. The first is that the MMG amplitude continues to increase up to $100 \%$ MVC due to a shift in slow-twitch motor unit recruitment to fast-twitch motor unit recruitment by high force exertion (Maton et al., 1990; Stokes and Dalton, 1991). The second is that the MMG amplitude in this region decreases because of a reduction in muscle dimension due to muscle stiffness (Orizio et al., 1989; Matheson et al., 1997). On the other hand, it is well documented that EMG amplitude increases proportionally up to $100 \%$ MVC (Orizio et al., 1989; Smith and Stokes, 1993). The present study, however, investigated the range of $20-80 \% \mathrm{MVC}$, and the RMS of EMG, MMG- ${ }_{\text {MIC }}$ and MMG- ${ }_{\text {ACC }}$ tended to increase with regard to $\% \mathrm{MVC}$ in the agonist muscles during flexion and extension (Fig. 2). From the above, it can be expected that the RMS amplitude of the MMG is similar to that of the EMG and the agonist RMS amplitude is higher than that of the antagonist, which shows relatively smaller activity. 
Flexion

Extension
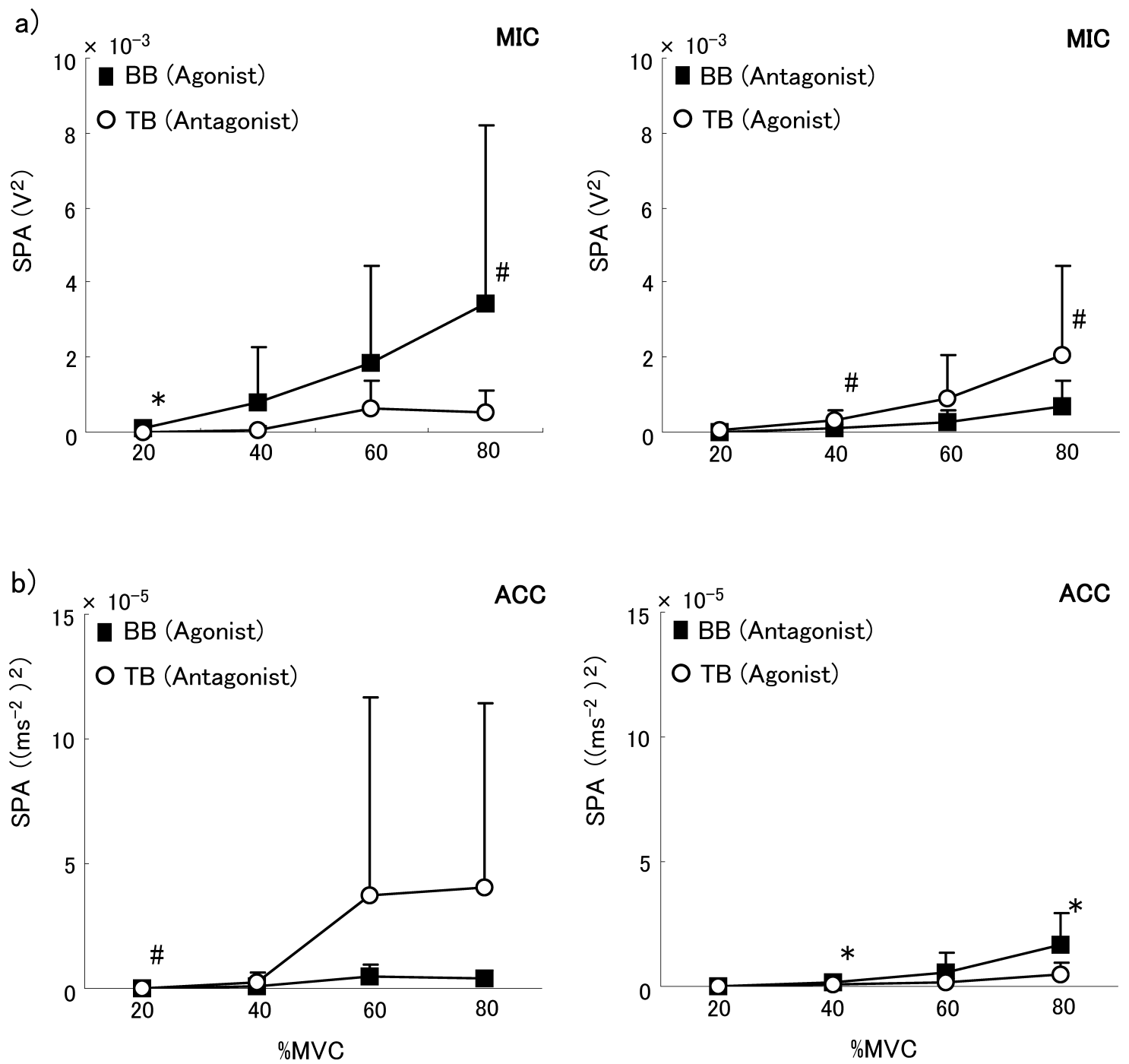

Fig. 4 Mean $( \pm$ SE) sum of power spectrum amplitude (SPA) values of the 8-12 Hz frequency bandwidth. a) SPA of the MMG recorded by microphone (MIC) during flexion [left panel] and extension [right panel]. b) SPA of the MMG recorded by accelerometer (ACC) during flexion [left panel] and extension [right panel]. $(*) p<0.05$, (\#) $p<0.1$ comparison between biceps brachii (BB) and triceps brachii (TB). MIC: $0 \mathrm{~dB}=1 \mathrm{~V} / \mathrm{Pa}, \mathrm{ACC}: 0 \mathrm{~dB}=1 \mathrm{~V} / 0.1 \mathrm{G}$.

In the present investigation, the RMS of the agonist MMGMIC was significantly $(p<0.05)$ higher than that of the antagonist during flexion and extension at each contraction level (Fig. 2b). This result is similar to EMG results (Figs. 2a, b). However, the antagonist RMS of MMG- ${ }_{\mathrm{ACC}}$ showed no significant $(p>0.05)$ difference with that of the agonist, or tended to be higher than that of the agonist (Fig. 2c). It has been suggested that the MMG signal might include FT and motion artifacts, which may affect the interpretation of MMG signals (Barry, 1987; Oster and Jaffe, 1980; Itoh et al., 2000; Goldenberg et al., 1991; Orizio, 1993; Tarata, 2003; Watakabe et al., 2001). Because different MMG transducers have different inherent characteristics, the influence of FT and motion artifacts may differ. Watakabe et al. (2001) compared the influence of motion artifacts on MMG signals recorded by an ACC and a MIC. They reported that the ACC can be more strongly affected by movement artifacts than can the MIC and recommend the use of a MIC to evaluate muscle activity with MMG during dynamic muscle contraction. Because motion artifacts occur in the lowest frequency bandwidth (Tarata, 2003), many researchers are using a high pass filter below approximately $5 \mathrm{~Hz}$ to remove motion artifacts and noise from MMG signals, even though it is impossible to completely eliminate such signals from MMG signals. In the present study the raw MMG signals of both transducers were filtered using a $3-100 \mathrm{~Hz}$ band-pass filter. Moreover, to reduce the influence of motion artifacts, the subject was asked to maintain his posture using a marker indicating the desired height of the forearm at 
an elbow joint angle of $90^{\circ}$. In addition, visual feedback was used to ensure that the hand's position remained stationary during the task (Fig. 1b). Therefore, the different MMG results of both transducers in the present study may be due more to the influence of FT than motion artifacts.

Previous studies have reported that isometric muscle contraction is accompanied by FT (Allum et al., 1978; Brown et al., 1982; Prochazka and Trend, 1988), and that FT contaminates MMG signals (Itoh et al., 2000; Goldenberg et al., 1991; Orizio, 1993; Barry, 1987). The muscle's natural frequency is in a low frequency bandwidth. Wakeling and Nigg (2001) demonstrated with low limb muscles that the natural frequency bandwidth of soft tissue on muscle is below $10 \mathrm{~Hz}$ in a relaxed state, and extends to $50 \mathrm{~Hz}$ during a fully active state. It has been reported that the FT occur in a frequency bandwidth as low as $1-25 \mathrm{~Hz}$ (Allum et al., 1978) and that most of the frequency bandwidth is between $3-6 \mathrm{~Hz}$ and $8-12$ $\mathrm{Hz}$ (Brown et al., 1982; Prochazka and Trend, 1988). Therefore, if the low-frequency mechanical vibration of FT is transmitted to soft tissue, the soft tissue should resonate and the MMG which records vibration on the skin surface could be affected by the mechanical vibration of FT.

In the present study, the different results of the RMS between $\mathrm{MMG}^{-}{ }_{\mathrm{MIC}}$ and $\mathrm{MMG}^{-}{ }_{\mathrm{ACC}}$ may suggest that the $\mathrm{ACC}$ is more strongly affected by FT than is the MIC. The SPA results may clearly show the different influence of FT on MMG recorded by the MIC and the ACC. The agonist SPA of $\mathrm{MMG}_{\text {MIC }}$ for $3-6 \mathrm{~Hz}$ and $8-12 \mathrm{~Hz}$ tended to be higher than that of the antagonist at each force level during flexion and extension (Figs. 3a, 4a). However, the SPA of MMG- ${ }_{\text {ACC }}$ between the agonist and antagonist showed no significant $(p>0.05)$ difference, or that of the antagonist tended to be higher than that of the agonist (Figs. 3b, 4b). This result may be due to the different inherent characteristics of the two MMG transducers in the MMG signal detecting system.

It has been suggested that the MMG signals detected using a MIC and ACC reflect the displacement and acceleration of the skin's vibration, respectively. Mathematically, each of the physical values of acceleration and displacement can be converted to the other's using integral or differential computation. Watakabe et al. (2001) proved that the amplitude spectral density function (ASD) of the MIC is similar to the double integral of the ACC transducer signal, and suggested that the MIC acts as a displacement meter in the MMG. The MMG signals recorded by a MIC and an ACC showed differences in frequency response (Orizio, 1993; Watakabe et al., 2001). The main MMG component detected by the ACC (up to $60 \mathrm{~Hz}$ ) is more widely distributed within the frequency bandwidth than that detected by the MIC (up to $40 \mathrm{~Hz}$ ). In addition, the MMG recorded by the MIC has a relatively higher ASD than does the ACC in a low frequency bandwidth, while the MMG recorded by the ACC is higher than the MIC in a high frequency bandwidth (Watakabe et al., 2001). The present study used MIC and ACC transducers that have a flat frequency response between 3 and $100 \mathrm{~Hz}$ (based on the manufacturers' specifications). However, the sensitivity of the MIC may be influenced by the size of its air chamber because the MIC detects the mechanical activity of the muscle via the air chamber. Watakabe et al. (2001) proved in a mechanical vibration test that the sensitivity of frequency response did not change if the air chamber is at least $10 \mathrm{~mm}$ in diameter and $15 \mathrm{~mm}$ in length, though there existed a cut-off frequency of 2-4 Hz. In the present study we used an air chamber of $10 \mathrm{~mm}$ in diameter and $15 \mathrm{~mm}$ in length. Therefore, we expected that

\section{Condenser microphone}
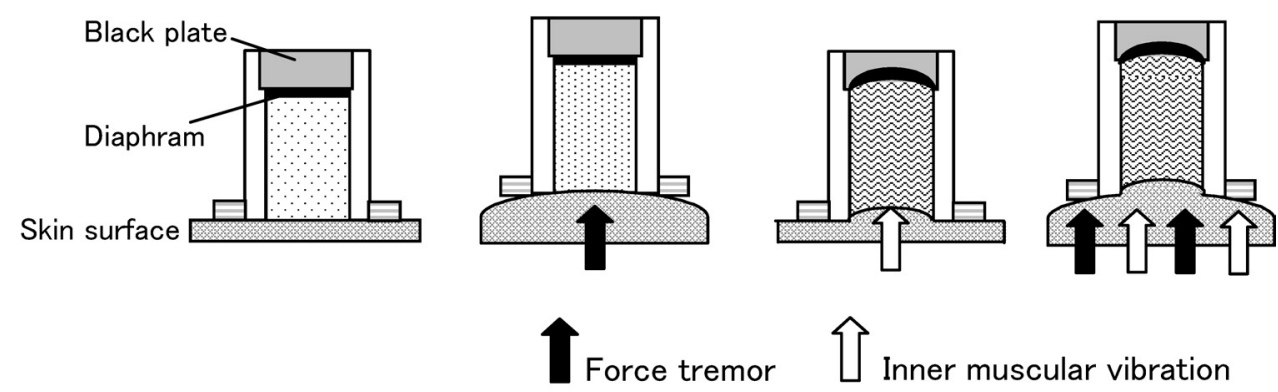

\section{Accelerometer}

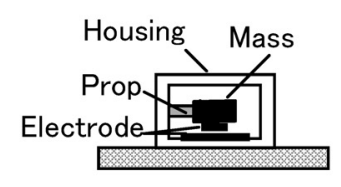

(a)

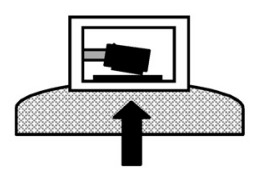

(b)

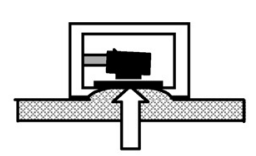

(c)

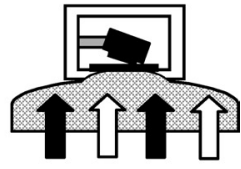

(d)

Fig. 5 Theoretical schematic drawings of a condenser microphone (MIC) and an accelerometer (ACC) on the surface of the skin during a) nonmuscle contraction, b) force tremor (FT), c) the detection of inner muscular vibration, and d) the detection of FT and inner muscular vibration at actual muscle contraction. 
there would be no difference in the relative sensitivity between the MIC and the ACC. However, the results at a frequency of $3-6 \mathrm{~Hz}$ in the MMG recorded by a MIC may have been influenced by the cut-off frequency of $2-4 \mathrm{~Hz}$.

In principle, the ACC consists of a housing, mass, a prop supporting the mass, and electrodes (Fig. 5a). Acceleration is detected as an electric change according to the change in distance between electrodes caused by the movement of the housing (Itoh et al., 2001). On the other hand, the MIC consists of a diaphragm and a back plate (Fig. 5a). Sound waves affect the capacitance between the back plate and the diaphragm, inducing an electric fluctuation on the back plate (Itoh et al., 2001). The MIC requires a chamber to measure the vibration of the skin surface as a change of air pressure. In other words, it senses the differential between the air in the air chamber and the cylinder (Fig. 5c). Theoretically, when the ACC is influenced by FT, the FT moves the ACC's housing, not the mass itself (Fig. 5b), and acceleration is detected at that time. On the other hand, all components of the MIC (i.e., the air chamber, condenser microphone, the air in the chamber, and the ring) are moved by FT as the skin's surface vibrates (Fig. $5 b)$. This may play a role in decreasing the influence of the FT. Watakabe et al. (2001) showed that the MIC does not generate an output signal when it is shaken. He also reported that the ACC is more affected by movement artifacts than is the MIC in a frequency range of less than $15 \mathrm{~Hz}$, and that the sensitivity of the MIC decreases more during muscle contraction than in a mechanical excitation test.

In the present study, the results regarding the RMS (Fig. 2c) and SPA (Figs. 3b, 4b) of MMG- ${ }_{\text {ACC }}$ could indicate that the soft tissue resonance ratio of antagonist muscle was larger than that of the agonist during flexion and extension. This may be because the agonist contraction activity is larger than that of the antagonist. The vibration characteristics of the soft tissues are changed by muscle activity (Wakeling and Nigg, 2001), and the resonance of soft tissue is damped by muscle activity (Wakeling et al., 2002). Thus, the antagonist may be more affected than the agonist by FT.

In conclusion, we investigated the influence of FT on the MMG recorded by an ACC and a MIC in the measurement of agonist and antagonist muscles during voluntary submaximal isometric contractions. We found that the RMS of the MMGMIC is similar to that of the EMG, while the amplitude of RMS in the agonist was greater than that in the antagonist. However, the results regarding the MMG- ${ }_{\mathrm{ACC}}$ were markedly different. A frequency analysis of the MMG- $_{\text {MIC }}$ and the MMG- ${ }_{\text {ACC }}$ suggested the possibility that the ACC is more strongly affected by FT than is the MIC. Therefore, the MMG detected by a MIC appears to be less affected by FT than is the ACC. Until now, several types of MMG transducer have been used to detect MMG signals without referring to guidelines regarding transducer selection. The results of the present study suggest that the MIC transducer is more effective than the ACC in research on the physiological mechanical aspects of antagonistic muscle pairs, even though it is difficult to eliminate the influence of FT on the MMG signal completely. In addition, the findings of the present study may be useful in the selection of an MMG sensor type when we simultaneously record MMGs of various muscles in which the influences of tremor may differ. Additional studies are needed that directly assess FT in both types of MMG transducer during isometric contractions of agonist-antagonist pairs.

\section{References}

Allum JH, Dietz V, Freund HJ (1978) Neuronal mechanisms underlying physiological tremor. J Neurophysiol 41: 557571

Barry DT, Geiringer SR, Ball RD (1985) Acoustic myography: a noninvasive monitor of motor unit fatigue. Muscle Nerve 8: 189-194

Barry DT (1987) Acoustic sounds from frog skeletal muscle. Biophys J 51: 769-773

Barry DT (1992) Vibrations and sounds from evoked muscle twitches. Electromyogr Clin Neurophysiol 32: 35-40

Beck TW, Housh TJ, Johnson GO, Weir JP, Cramer JT, Coburn JW, Malek MH (2006) Comparison of a piezoelectric contact sensor and an accelerometer for examining mechanomyographic amplitude and mean power frequency versus torque relationships during isokinetic and isometric muscle actions of the biceps brachii. J Electromyogr Kinesiol 16: 324-335

Bernardi M, Solomonow M, Baratta RV (1997) Motor unit recruitment strategy of antagonist muscle pair during linearly increasing contraction. Electromyogr Clin Neurophysiol 37: 3-12

Bolton CF, Parkes A, Thompson TR, Clark MR, Sterne CJ (1989) Recording sound from human skeletal muscle: technical and physiological aspects. Muscle Nerve 12: 126134

Brown TI, Rack PM, Ross HF (1982) Different types of tremor in the human thumb. J Physiol 332: 113-123

Cescon C, Farina D, Gobbo M, Merletti R, Orizio C (2004) Effect of accelerometer location on mechanomyogram variables during voluntary, constant-force contractions in three human muscles. Med Biol Eng Comput 42: 121-128

De Luca CJ (1997) The use of surface electromyography in biomechanics. J Appl Biomech 13: 135-163

De Vito G, McHugh D, Macaluso A, Riches PE (2003) Is the coactivation of biceps femoris during isometric knee extension affected by adiposity in healthy young humans. J Electromyogr Kinesiol 13: 425-431

Ebenbichler GR, Kollmitzer J, Glockler L, Bochdansky T, Kopf A, Fialka V (1998) The role of the biarticular agonist and cocontracting antagonist pair in isometric muscle fatigue. Muscle Nerve 21: 1706-1713

Gamet D, Maton B (1989) The fatigability of two agonistic muscles in human isometric voluntary submaximal contraction: an EMG study. I. Assessment of muscular fatigue by means of surface EMG. Eur J Appl Physiol 
Occup Physiol 58: 361-368

Goldenberg MS, Yack HJ, Cerny FJ, Burton HW (1991) Acoustic myography as an indicator of force during sustained contractions of a small hand muscle. J Appl Physiol 70: 87-91

Gordon G, Holbourn AH (1948) The sounds from single motor units in a contracting muscle. J Physiol 107: 456-464

Itoh Y, Akataki K, Mita K (2000) Spectrum analysis of the mechanomyogram: elimination of the longitudinal shortening component of muscle fibers. Syst Comput Jpn 31: 57-64

Itoh Y, Watakabe M, Akataki K, Mita K (2001) Physical characteristics of transducers for measuring mechanomyogram. IEICE Trans Fundamentals J84-D-II: 408-416 [In Japanese]

Jaskolska A, Madeleine P, Jaskolski A, Kisiel-Sajewicz K, Arendt-Nielsen L (2007) A comparison between mechanomyographic condenser microphone and accelerometer measurement during submaximal isometric, concentric and eccentric contractions. J Electomyogr Kinesiol 17: 336-347

Maton B, Petitjean M, Cnockaert JC (1990) Phonomyogram and electromyogram relationships with isometric force reinvestigated in man. Eur J Appl Physiol Occup Physiol 60: 194-201

Milner TE, Cloutier C, Leger AB, Franklin DW (1995) Inability to activate muscles maximally during cocontraction and the effect on joint stiffness. Exp Brain Res 107: 293305

Mamaghani NK, Shimomura Y, Iwanaga K, Katsuura T (2001) Changes in surface EMG and acoustic myogram parameters during static fatiguing contractions until exhaustion: Influence of elbow joint angles. J Physiol Anthropol Appl Human Sci 20: 131-140

Matheson GO, Maffey-Ward L, Mooney M, Ladly K, Fung T, Zhang Y (1997) Vibromyography as a quantitative measure of muscle force production. Scand J Rehabil Med 29: 29-35

Orizio C (1993) Muscle sound: bases for the introduction of mechanomyographic signal in muscle studies. Crit Rev Biomed Eng 21: 201-243

Orizio C (2004) Surface mechanomyogram. In Merletti R, Parker P eds. Electromyography, Physiology, engineering and noninvasive applications. 21st ed., IEEE Press John Wiley \& Sons, Hoboken, 305-322

Orizio C, Perini R, Veicsteinas A (1989) Muscular sound and force relationship during isometric contraction in man. Eur J Appl Physiol Occup Physiol 58: 528-533
Oster G, Jaffe J (1980) Low frequency sounds from sustained contractions of human skeletal muscle. Biophys J 30: 119127

Prochazka A, Trend PS (1988) Instability in human forearm movements studied with feedback-controlled muscle vibration. J Physiol 402: 421-442

Psek JA, Cafarelli E (1993) Behavior of coactive muscles during fatigue. J Appl Physiol 74: 170-175

Shibata M, Moritani T (1991) The mechanism of electromyographic silent periods preceding a ballistic voluntary planter flexion. Ann Physiol Anthropol 10: 211218 [In Japanese with English Abstract]

Smith AM (1981) The coactivation of antagonist muscles. Can J Physiol Pharmacol 59: 733-747

Smith TG, Stokes MJ (1993) Technical aspects of acoustic myography of human skeletal muscle: contact pressure and force/AMG relationships. J Neurosci Methods 47: 85-92

Stokes MJ, Dalton PA (1991) Acoustic myography for investigating human skeletal muscle fatigue. J Appl Physiol 71: 1422-1426

Tarata M, Spaepen A, Puers R, Hermans V (1997) The potential of simultaneously recording the EMG and muscle mechanical vibrations in monitoring the muscle behavior. In Proc Int Conf Measurement, Smolenice, Slovak republic, $1-4$

Tarata M (2003) Mechanomyography versus electromyography, in monitoring the muscular fatigue. Biomed Eng Online: 2: 3

Wakeling JM, Nigg BM (2001) Modification of soft tissue vibrations in the leg by muscular activity. J Appl Physiol 90: $412-420$

Wakeling JM, Nigg BM, Rozitis AI (2002) Muscle activity damps the soft tissue resonance that occurs in response to pulsed and continuous vibrations. J Appl Physiol 93: 10931103

Watakabe M, Mita K, Akataki K, Itoh Y (2001) Mechanical behaviour of condenser microphone in mechanomyography. Med Biol Eng Comput 39: 195-201

Received: April 11, 2007

Accepted: November 21, 2007

Correspondence to: Tae-Kwang Kim, Graduate School of Science and Technology, Chiba University, 1-33 Yayoi-cho, Inage-ku, Chiba 263-8522, Japan

Phone: +81-43-290-3084

Fax: +81-43-290-3087

e-mail: caravans@graduate.chiba-u.jp 